Goldschmidt 2021 Abstract

https://doi.org/10.7185/gold2021.7730

\section{Chlorine isotopes in La Soufrière de Guadeloupe (FWI) fumaroles trace HCl scrubbing at shallow depth}

ETIENNE LE GLAS ${ }^{1}$, MAGALI BONIFACIE ${ }^{2}$, PIERRE AGRINIER $^{3}$, GERARD BARDOUX ${ }^{4}$, ROBERTO MORETTI ${ }^{5}$, DR. JABRANE LABIDI ${ }^{6}$ AND VINCENT ROBERT ${ }^{6}$

${ }^{1}$ Institut de Physique du Globe de Paris /CNRS UMR 7154

${ }^{2}$ IPGP/CNRS UMR 7154

${ }^{3}$ Université de Paris, Institut de Physique du Globe de Paris, CNRS UMR 7154

${ }^{4}$ Université de Paris, Institut de Physique du Globe de Paris, CNRS

${ }^{5}$ Université de Paris, Institut de Physique du Globe de Paris /

Obs. Volcanol. Sismol. Guadeloupe

${ }^{6}$ Institut de Physique du Globe de Paris

Presenting Author: leglas@ipgp.fr

For volcanoes with large hydrothermal system, it is challenging to constrain the initial volcanic gases composition (i.e. before hydrothermal interaction) particularly for $\mathrm{SO}_{2}$ and $\mathrm{HCl}$ because of their solubilization in waters (scrubbing). Chlorine is highly soluble in waters and chemically considered as mainly non-reactive (unlike $\mathrm{SO}_{2}$ ), and thus can inimitably trace interactions between gases and waters. Furthermore, large $\mathrm{Cl}$ isotope fractionations in volcanic systems should only occur during evaporation and/or vapor condensation [1].

Here, we investigate for the first time the potential of $837 \mathrm{Cl}$ to constrain scrubbing on a suite of samples (condensates and Giggenbach bottles collected from 2018 to present) from la Soufrière de Guadeloupe (FWI) summit fumaroles. This volcano has developed a large hydrothermal system in which transient thermobarometric fluctuations may determine rapid accelerations of the ongoing unrest [2]. This activity culminated in April 2018 with the occurrence of a $4.1 \mathrm{M}$ earthquake, which was considered as a failed phreatic eruption determined by the hydrothermal overpressure due to a magmatic gas pulse [2].

We find $\delta 37 \mathrm{Cl}$ preliminary data of fumarolic samples that vary from 0.6 to $11.7 \%$. To interpret this variation, we designed an $\mathrm{HCl}$ boiling experiment that shows that vapor/liquid chlorine isotopes partitioning occurs at thermodynamic equilibrium over boiling, with a fractionation of $\Delta$ vapor-liquid $=1.5 \%$. Assuming that the deep aquifer brines have $\delta 37 \mathrm{Cl}$ of $-1 \%$, based on summit acid pond $\delta 37 \mathrm{Cl}$ value, we calculate that the starting $\delta 37 \mathrm{Cl}$ value of HClgas is $\sim 0.5 \%$ prior to subsurface scrubbing. Assuming that partial HClgas condensation via scrubbing occurs under the same equilibrium conditions than boiling and follows a Rayleigh distillation law, we model the $837 \mathrm{Cl}$ value of remaining HClgas for every HClgas lost fraction. Fumarolic samples with $837 \mathrm{Cl}$ from 0.6 to $11.7 \%$ would require 6 to $99 \%$ HClgas removal via subsurface scrubbing. Further investigations will help to refine these quantifications and to better understand why scrubbing rates vary so much. Our $837 \mathrm{Cl}$ dataset will also be closely compared to more conventional geochemical indicators of volcanic gas compositions [2] to link the observed $837 \mathrm{Cl}$ variations with magmatic and rainfall forcing.
References:

[1] Schauble et al. 2003, GCA

[2] Moretti et al., 2020, JVGR 